limits to involuntary commitment; for example, it may not be indefinite (as it was before the 1960s).

There is no legal discrimination against people with mental disorders but they are nevertheless discriminated against in other ways. Since 1990, because of financial problems, few patients have been able to find employment. The tolerance of society has decreased. Since 1990 it has been necessary to create committees to investigate abuse during involuntary commitment. $0 \mathrm{n}$ the other hand, before 1990 some individuals with (and even some without) mental disorders were committed to a psychiatric department to protect them.

\section{Conclusions}

o In Romania, there is a push to re-orientate mental services from being centred on hospitals towards a community care focus.

o People with chronic mental disorders, including dementia, are taken care of both in long-stay psychiatric hospitals and by social services, where the personnel are inadequately trained to care for them.

- Stigma remains an obstacle in ensuring access to care for patients with a mental illness. The battle against stigmatisation needs to be prioritised.

o There is considerable room for improvement in education and training in psychiatry, in research, and in the promotion of mental health and illness prevention.

o It is important for the future development of community services to distinguish between care and treatment.

o The basic quality of care for those who are mentally ill needs to be improved by: developing a community psychiatric network based on geographical catchment areas; developing a complex rehabilitation programme with more substantial social and financial support; involving the community, carers and users more; and involving the government and local authorities in mental healthcare.

In Romania, as in all former communist countries, there are economic problems and a need for national fundraising to support national psychiatric organisations and services.

\section{References}

Camus, V., Katona, C., De Mendonca Lima, C. A., et al (2003) Teaching and training in old age psychiatry: a general survey of the World Psychiatric Association member societies. International Journal of Geriatric Psychiatry, 18, 694-699.

Tataru, N . (1997) Project for the development of an ambulatory and semi-ambulatory centre for the third age. Dementia and Geriatric Cognitive Disorders, 8, 128-131.

World Health Organization, Division on Mental Health and Prevention of Substance Abuse (1996) Psychiatry of the Elderly - A Consensus Statement. Geneva: WHO.

\title{
Mental health services in Uganda
}

\section{Fred Kigozi}

Medical Director/Senior Consultant Psychiatrist, Butabika National Referral Teaching Hospital, email: buthosp@infocom.co.ug

ganda is a landlocked developing country in East Africa with an estimated population of 24.8 million people (2002 census). At independence (in 1962) U ganda was a very prosperous and stable country, with enviable medical services in the region. This, however, was destroyed by a tyrant military regime and the subsequent civil wars up to 1986, when the current government took over the reigns of power.

The 2000/2001 U ganda D emographic and $\mathrm{H}$ ealth Survey (UDHS) and the 2002 census report revealed several poor demographic and health indicators. The data showed a high population grow th rate (in excess of 3\% per annum) due to the high fertility rate, estimated at seven children per woman. The age structure is therefore young, with about half the population below 15 years of age. The infant mortality rate was 88 per 1000 live births and maternal mortality rate 50.4 per 10000 live births. Life expectancy was 43 years. Gross domestic product (GDP) per capita was around U $\$ 300$.

By the mid-1980s, the economy had been destroyed and many of the medical personnel had left the country. The net effect was the current low GDP and poor health indices, which, how ever, have gradually improved over the last decade or so. The continuing civil wars in the north and north-eastern parts of the country continue to drain valuable national resources, and the affected areas have very poor socio-demographic and health indices. The net effect has been a dilapidated infrastructure and psychosocial problems, mainly manifesting as posttraumatic stress disorders.

$U$ ganda is one of the countries in sub-Saharan Africa that was hard hit by the HIV/AIDS epidemic; however, with a sound government strategy and a timely response, HIV infection has been reduced from a prevalence of $20-28 \%$ in the mid-1980s to the current $5.6 \%$. U ganda
There is no legal discrimination

against persons with mental

disorders but they

are nevertheless

discriminated

against in other

ways. Since 1990,

because of

financial

problems, few

patients have

been able to find

employment. The

tolerance of

society has

decreased.

Uganda ... was

hard hit by the

HIV/AIDS epi-

demic; however,

HIV infection

has been reduced

from a prevalence

of $20-28 \%$ in the

mid-1980s to the

current $5.6 \%$.

Uganda stands as

one of the few

developing

countries that has

succeeded in

reversing the tide

of the HIV

epidemic. 
stands as one of the few developing countries that has succeeded in reversing the tide of the HIV epidemic (UN AID S, 2004).

\section{Health reforms}

The government has developed a new health policy (1999) and health sector strategic plan (2000), for which primary healthcare (PHC) was the basic philosophy and strategy for national health development, so that equitable services could be offered to the population. The policy emphasises a strong partnership approach between the public and private sectors, nongovernmental organisations ( $\mathrm{NGOs}$ ) and traditional practitioners, while safeguarding the identity of each stakeholder. Under the health policy, a basic minimum healthcare package was formulated, in which mental health was a key element, to be delivered at all levels of the health service.

\section{Brief history of mental health services}

U ganda has been offering some care for people with a mental illness since the 1920s. Initially these were rudimentary services based on custo dial confinement in the south-western part of the country. Better care was started in the capital, Kampala, in the 1930s, followed by modern psychiatric services at the then newly built national referral psychiatric hospital, Butabika H ospital, on the outskirts of the capital in the mid-1950s.

\section{Mental health programme and services}

The current challenges to $U$ gandan psychiatry and the delivery of mental health services include the continued civil wars in the north and north-eastern parts of the country (where the prevalence of post-traumatic stress disorders is very high) and the psychosocial effects of HIV/AID S (Boardman \& 0 vuga, 1997). There is rapid migration of people to urban areas but no corresponding job opportunities. The poverty levels and illiteracy rates are high as well. Consequently, the country experiences a high burden of psychosocial problems in addition to traditional mental health disorders. How ever, the government attaches great importance to improving mental health services so as to address the burden of mental health problems.

The mental health programme was formulated in 1996 and revised in 2000, following the above health reforms. Its main objective is to provide improved access to primary mental health services for the entire population and to ensure ready access to quality mental health referral services at district, regional and national levels. The strategy incorporates both a remodelling of the infrastructure and the provision of the required human resources through the training of specialists and retraining of general health workers.

Mental health services have been decentralised and also integrated within the general healthcare delivery systems and primary health care. The result has been a structure that promotes equity of access by all U gandan citizens to some mental health interventions, including preventive and rehabilitative services. The process encourages orderly referrals from village level (health centre I), through parish (health centre II), sub-county (health centre III) and county (health centre IV) to district hospitals and regional referral hospitals up to the national referral teaching hospitals at Butabika and Mulago.

At the lower levels (up to the district hospital), clients requiring mental health services are generally managed together in an integrated way, with all other patients, at both out-patient and in-patient facilities. Specialisation and separation begin at the regional referral hospitals, where both physicians and psychiatric clinical officers are usually available. At the regional referral hospitals, 22-32 beds are available, as are an out-patient department and community outreach services.

At the apex of mental healthcare delivery are Butabika and Mulago hospitals, and the Division of Mental $\mathrm{H}$ ealth at the Ministry of $\mathrm{H}$ ealth. Butabika H ospital is the national referral mental hospital, and therefore offers tertiary mental health services. These include curative, preventive and rehabilitative psychiatric services. Mulago is the national referral general hospital. It has a 50-bed psychiatric ward run by the department of psychiatry, which offers active in-patient and outpatient care. There is also a consultation- liaison psychiatric service in the general wards. The Division of Mental $\mathrm{H}$ ealth at the Ministry of $\mathrm{H}$ ealth headquarters, headed by a principal medical officer, coordinates all the mental health activities in the country.

There is, though, an imbalance in the deployment of specialist personnel. All 18 psychiatrists are deployed in the capital city, save for one at M barara U niversity. The situation is the same for the few psychologists and psychiatric social workers in the country. This is in the process of being revised: a policy has been developed to post those psychiatrists and social workers who are about to complete their postgraduate courses to all 11 regional mental health units.

In addition to the above government structure is a large support system throughout the country based on N GO health facilities (hospitals and dispensaries) as well as non-facility N GO s. These are encouraged and supported to offer mental health services within their catchment areas, such as supportive psychotherapy and counselling services, in addition to the usual treatment programmes.

All psychiatric patients seen in the public sector receive free psychiatric services, including the basic psychiatric drugs.

Because of stigma and discrimination in the past, many $U$ gandans had been denied mental healthcare by their relatives or carers and the system, which was not welcoming. This is no longer tolerated. Mental health advocacy is offered by several consumer organisations, and this is gradually coming to play a significant role, though its effect is still generally seen only in urban areas. 
Postgraduate training in

psychiatry has been ongoing at Makerere Medical School but with relatively few enrolments, as most resident doctors have preferred to

specialise in other branches of medicine. This situation has begun to change in recent years.
The child and adolescent psychiatry course for postgraduates teaches clinical description, aetiology, recognition, diagnosis and specialist management of the

\section{Psychiatric association}

The U ganda Psychiatric Association (UPA) has been in existence since 1996 and members have regularly met at its scientific congresses, sometimes with other regional associations. Membership includes all psychiatrists practising in U ganda, while other mental health workers, such as psychiatric clinical officers, psychologists and psychiatric social workers, have been accorded associate membership status. The UPA carries out a number of education activities and anti-stigma programmes, in collaboration with mental health consumer groups and $N G O$ s, such as Mental Health U ganda, the U ganda Epilepsy Support Association and the U ganda Schizophrenia Fellowship.

The UPA is a member of the World Psychiatric Association (WPA) and its current President is also the W PA representative for Zone 14 (Eastern and Southern Africa) to the WPA executive committee.

\section{Mental health law reform}

U ganda has had a Mental Health Act since independence in 1962; it was revised in 1964. The main emphasis was custodial care, safeguarding the security of patients and the public, and the protection of the property of people who have a mental illness. The Act is currently being reviewed by a select ministerial committee, to bring it in line with modern mental health legislation. Two members of this team attended a series of workshops on mental health legislation organised by the World Health $\mathrm{O}$ rganization (WHO) in N orth Africa and Geneva. The new Bill has as its guiding principle the human rights of those who are mentally ill, including privacy, consent to treatment and conditions for involuntary admission. It critical skills appraisal, clinical skills and phenomenology. Courses are also offered in psychological therapies, forensic/administrative psychiatry, organic psychiatry, old age psychiatry, addiction psychiatry, community psychiatry, general adult psychiatry and consultation-liaison psychiatry. Research methods and epidemiology are also taught

\begin{abstract}
various psychiatric disorders encountered among children and adolescents. The course covers practical skills, including investigations, psychotherapy, drug treatment and mental health promotion in children and adolescents.

The course on psychological therapies teaches the principles and practice of psychological methods of treatment in general terms, but also highlights specific psychotherapies found to be relevant to U ganda (i.e. behavioural therapy, marital therapy, family therapy, supportive psychotherapy and child psychotherapy). Classical psychoanalysis is covered theoretically.

Research in psychiatry has been undertaken over the years in epidemiology, clinical psychiatry and social psychiatry. Current research areas include the epidemiology of suicide in U ganda, prenatal depression, psychosocial effects among the displaced population in northern U ganda, and alcohol and drug use among the secondarystudent population in the central region of $U$ ganda (to mention but a few). There is also collaborative research being undertaken in HIV/AIDS with Case Western Reserve U niversity. ward rounds, tutorials and so on. Administrative
psychiatry and the management of psychiatric problems
\end{abstract} are recess semesters in the first and second years. Much of the training involves clinical apprenticeship, whereby intervin is required to carry out psychitic psychotherapy under supervision. The other methods of teaching are lectures, tutorials, interactive discussions and tations. Courses are offered in: advanced anatomy, neuropathology, and psychopharmacology, as well as 
gives experts a bigger role in decision making based on professional psychiatric assessment, without compromising the rights of the patient. It establishes an independent mental health tribunal, a national mental health coordination committee and district mental health coordinating committees. The role of the judiciary and the police is clearly defined. The passing of this Bill will greatly enhance psychiatric care and safeguard the rights of people who are mentally ill.

\section{Conclusions}

- U ganda is a low-income country that has recently begun to emerge from decades of civil strife and wars.

- It has a high level of poverty and low literacy rates, as well as a high proportion of young people.

o There is a significant burden of mental health problems, worsened by the psychosocial effects of civil wars and the HIV/AIDS pandemic.

O Health reforms in the past 5 years or so, together with formulation of the national mental health policy, have led to a sizeable investment in education and training as well as infrastructure in the mental health sector.

o The challenges that remain concern: the integration of mental health into primary healthcare, which has to overcome some resistance and issues of stigma; the inadequate number of specialists (psychiatrists, clinical psychologists, psychiatric social workers); the limited availability of newer psychiatric drugs; mental health promotion and prevention; improved education and training in psychiatry; and the limited awareness of mental health consumers of their rights.

\section{References and further reading}

Boardman, J. \& O vuga, E. B. L. (1997) Rebuilding psychiatry in U ganda. Psychiatric Bulletin, 21, 649-655.

Bolton, P., Bass, J., Neugebauer, R., et al (2003) Group interpersonal psychotherapy for depression in rural U ganda: a randomized controlled trial. Journal of the American Medical Association, 289, 3117-3124.

Kigozi, F., Kinyanda, E. \& Kasirye, R. (1999) Street children in Uganda: a product and a high risk group for HIV/AIDS. Southern African Journal of Child and Adolescent Mental Health, 2.

Kinyanda, E. (1998) Frequency with which psychiatric disorder is associated with a positive HIV-1 serostatus as seen in persons attending a TASO clinic in Mulago. South Africa Medical Journal, 88, 1178 .

Kinyanda, E. \& Musisi, S. (2001) War traumatisation and its psychological consequences on the women of Gulu district. In Medical Interventional Study of War Affected Gulu District, U ganda. Kampala: ISIS-WICCE.

Kinyanda, E., Hejelmeland, H. \& Musisi, S. (2004) Deliberate self-harm as seen in Kampala, U ganda: a case-control study. Social Psychiatry and Psychiatric Epidemiology, 39, 318-325.

Musisi, S. \& Kinyanda, E. (2000) Psychiatric Problems of HIV/ AIDS and Their Management in U ganda. A Book for Primary Health Care Workers. Kampala: STIP/Ministry of Health.

Musisi, S., Kinyanda, E., Leibling, H., et al (1998) The psychological consequences of war traumatisation on women of Luwero district, U ganda. In Short Term Intervention of the Psychological and Gynaecological Consequences of Armed Conflict in Luwero District. Kampala: ISIS-W ICCE.

Musisi, S., Tugumisirize, J., Kinyanda, E., et al (2001) Psychiatric consultation liaison at Mulago Hospital, Kampala U ganda. Makerere University Medical School Journal, 35, 4-11.

UNAIDS (2004) 4th Report on the Global AIDS Epidemic. Geneva: UNAIDS.
This paper was presented at the annual meeting of the Royal College of Psychiatrists, Harrogate, UK, 2004.

\section{Some cultural aspects of the Arab patient-doctor relationship}

\section{Fakhr El-Islam}

Academic Consultant, Behman Hospital, Helwan, Cairo, Egypt, email: info@behman.com.

ulture is a socially shared, trans-generationally transmitted system of implicit values, beliefs and attitudes and explicit behavioural practices (Kroeber \& Kluckhohn, 1952). It includes religion. Culturally based assumptions infiltrate the patientdoctor relationship.

\section{The doctor as the 'other'}

Patients transfer to doctors culture-based attitudes related to the doctor's gender and age. A female patient may avoid eye contact with a male doctor because this is culturally polite and respectful. A male patient may not report any weakness (e.g. fears, tearfulness or sexual inadequacy) to a female doctor. During family therapy for intergenerational conflict (El-Islam et al, 1986), children are likely to expect the doctor to have the same attitudes as their parents, and members of the parental generation are often surprised when the doctor does not oppose children's attempts to depart from their cultural heritage. Good doctors are generally expected to be authoritarian to some extent and their instructions directly advisory rather than a choice or an invitation to reflect (e.g. about alternative methods of treatment). Patients expect doctors to take their side in conflicts with family members, employers and public authorities. 